\title{
Women and children's well-being in Indian nuclear families during the COVID-19 pandemic
}

\author{
Richa Rana', Ridhi Sood ${ }^{2}$, Sonali Bhardwaj ${ }^{3}$
}

\begin{abstract}
The culture of living in a nuclear family setting, a norm of modernisation, has been badly shaken by the outbreak of the COVID-19 pandemic. This hit has created many pauses and changes in women's lives who live in nuclear families with the responsibility of taking care of very young children. Despite the various discussions related to women during the pandemic, there seem to be negligible efforts to understand the lived reality of nuclear family women having the responsibility of child care. The idea of living in this type of family is based on the thinking that it provides ample opportunity to develop individual talents and lead an unrestricted life. However, it can have a very adverse effect on women and children during the pandemic due to the closure of essential support systems such as child care centres and schools. Thus, this situation has a negative effect on the lives of women, which in turn, affects their young children's lives too. This study explored the lived experiences of a purposively selected sample of six women regarding challenges to deal with an office job, domestic work, and child care during the ongoing pandemic. Data were generated by conducting the telephonic semi-structured interview and thematic analysis was used to analyse the data. Results indicate the curtailment of freedom and choices, adverse impact on the mental and physical health of women and their children
\end{abstract}

\author{
Article History \\ Received: 31 May 2021 \\ Accepted: 12 July 2021
}

Keywords

Childcare; COVID-19;

Education; Mental health;

Women

\section{Introduction}

The COVID-19 pandemic has induced an unprecedented, uncertain, and frightening condition worldwide, including in India. Here, from March 2020 onwards, a newly chaotic world has developed where lockdown, unlock down, mounting infection cases, and human casualties all affect life and survival. The Lancet (2021) pointed out that till 4th May 2021, more than 20.2 million contagious cases have been reported here. Moreover, the slow process of vaccination and no provision of vaccination for children has created an acute panic and a grim reality for everyone. This crisis has put India in a very vulnerable situation, especially for women and children. The recent United Nations Development Programme ([UNDP]2020) "COVID-19 Global Gender Response Tracker" indicates unequal policy response to women's economic security and unpaid caring at the global level. It may moderate progress on gender equality earned in recent decades, and that work-related gender inequality may be heightened. Further, it claims that many countries are not successfully able to shield women from the negative social and economic repercussions of the current pandemic.

During all these lockdown phases, women and young children have emerged as a salient vulnerable group. A United Nations ([UN]2020) report "Policy Brief: The Impact of COVID-19 on Women"asserts that women have been carrying a heightened burden of caring in this pandemic due to the closure of early childhood care and education centres. Correspondingly, children's development and care are also on the verge of a big new crisis that may be responsible for multifarious types of changes and challenges in young

\footnotetext{
${ }^{1}$ Jawaharlal Nehru University, Zakir Husain Centre for Educational Studies, New Delhi, India, e-mail: richarana.121985@gmail.com, ORCID: https://orcid.org/0000-0001-6477$\underline{9381}$

${ }^{2}$ Jamia Millia Islamia University, Department of Educational Studies, New Delhi, India, e-mail: ridhisood22@gmail.com, ORCID: https://orcid.org/0000-0002-8503-5506 ${ }^{3}$ Jawaharlal Nehru University, Zakir Husain Centre for Educational Studies, New Delhi, India, e-mail: sonalibhardwaj78@gmail.com, ORCID: https://orcid.org/0000-0002-8319$\underline{7579}$
} 
ones' lives. These changes are atypical, create helplessness and vulnerability and jeopardise the overall well-being of individuals. A recent report of the United Nations (Gromada, Richardson, \& Rees, 2020) also call this pandemic a global childcare crisis, where women are very less likely to receive social protection due to the closure of early childhood care centres (International Labour Organization [ILO], 2020) and complex gender norms. All these circumstances have also been presenting additional tasks and challenges in families, especially to women.

In the present scenario, various forms of families exist in Indian society, where the nuclear family type is the most prominent one. Living in a nuclear family has become a norm of modern Indian society (Singh, 2003; Verma, 1995 cited in Suppal \& Roopnarine, 1999). With no consensus over the definition of multilayered nature, it has emerged as a salient type of family in urban India (Chakravorty, Goli, \& James, 2021; Singh, 2003); such as single-headed family, stem nuclear family, nuclear family in urban areas having a joint family as a fountainhead, represent its varied silhouette (Singh, 2003; Uberoi, 2014 cited in Chakravorty et al., 2021). The nuclear family exists in between traditionalism and modernity and highly embraces the egalitarian principle. In this type of family, individualism and personal interest diminish traditional roles and disintegrate kinship and relationship. Increased healthcare opportunities, extended control over mobility, and power resulting in safer matrimonial homes for women are some features that popularise the nuclear family concept (Allendorf, 2013; Chakravortyet al., 2021; Narayan \& Bhardwaj, 2005). However, there is another side of the reality, where women are entirely dependent on outside agencies to pursue their familial and professional goals.

These women also comprise the most vulnerable group and are supposed to be filled with fluid personality characteristics every time (Scharff, 2015), even during the pandemic. Although they differ on the basis of their socio-economic status, work, and family structure; but, childcare is unanimously viewed as their sole responsibility. Therefore, women belonging to a nuclear family with young children in India can be understood as a highly vulnerable group. They have less support and totally depend on the child care centres and maidservants to take care of children, household works, and continue their profession (Tuli \& Chaudhary, 2010). As these facilities are no longer available due to lockdown, women's and their children's well-being are more prone to get adversely affected by the current pandemic. Thus, a unique and urgent call is emerging to understand the impact of the pandemic-induced lockdown on women's and their young children's overall well-being. This type of exploration may help to recognise how women and children are best assisted by identifying their reciprocal nature of changes and challenges. Therefore, based on the mentioned understanding, we can operationalise that a nuclear family is the convergence of a married woman with her spouse and unmarried children, both dual earners, relied on outside agencies for childcare, external services, and support systems. A scarcity of research can be noticed (for example Tiwari et al., 2020) in understanding nuclear family women's experiences having child care responsibility during the pandemic. Given the situation of studies in this area, the present study attempted to explore nuclear family women's experiences related to childcare.

\section{Method}

The present study explored women's lived experiences with child care during this pandemic. It adopted a qualitative research design. The data were collected by using the semi-structured interviews personally by each of the three researchers. This type of interview facilitates the researcher to know about a specific aspect of participants' life or experiences (Willig, 2013). Before conducting the interview, each participant was requested to read and fill in the consent form, and permission for recording the interview was obtained from the participant before starting the data collection process. Allthe interviews were conducted using mobile phones with a recording facility.

This study is based on the lived experiences of six purposively chosen women from nuclear families (age range 30-37 years) having at least one child in the early childhood stage. These male-headed nuclear families consisted of married women, husbands, and unmarried children. Out of six families, four families consisted of four members, and two were having five and three members, respectively. Bothpartners employed and depended on outside agencies, friends, or relatives for childcare and other household 
support. Out of six participants, five were from the middle social class and one from the lower social class. For ascertaining the social class of the participants, subjective indicators were used. The subjective view about social class is the perception of a person's position compared with other members of the society (Anderson, Kraus, Galinsky, \& Keltner, 2012). Three participants lived in their own homes, two were residing in rented accommodation, and one was availing a government service apartment facility. These participants worked in different job sectors before the pandemic, but two out of six had to decide to quit the job due to exacerbated child caring responsibility and closure of early childhood facilities. The one participant from a lower social class, including her husband, was hit hard by job loss during the pandemic. All these women belonged to three cities of India, namely Delhi, Bengaluru, and Lucknow; Delhi is the country's capital, and the other two cities are the state's capital. These cities were severely affected by the coronavirus in the second wave in April-May 2021.

The questions for the semi-structured interviews were formulated after carefully reviewing the relevant literature. The questions were sequenced to get information about the nature of responsibilities, activities, and various management strategies these women undertook during the pandemic. As countrywide lockdown and people were practising physical distancing, telephonic interviews were considered suitable for collecting data. The researchers asked the question in Hindi and English as per the participants' needs. The participation of all women was voluntary, and they were given a complete choice not to answer any specific question or all the questions. Socially desirable responses were carefully observed, and wherever there was evidence of this kind of response, the researchers tried to get the responses based on real experiences by constructing the questions differently. Identity-sensitive words and leading questions were avoided. The pseudonyms were used to maintain the confidentiality of participants (See Table 1 for background information of participants).

Table 1.Demographic Characteristics of Women, their Children and Spouse

\begin{tabular}{|c|c|c|c|c|c|c|c|c|c|c|c|c|}
\hline & & & & & Women & & & Children & & & & Spouse \\
\hline $\mathrm{N}$ & $\begin{array}{l}\text { Pseudo } \\
\text { name }\end{array}$ & Age & Education & $\begin{array}{l}\text { Socio- } \\
\text { economic } \\
\text { class }\end{array}$ & State & $\begin{array}{l}\text { Working } \\
\text { status }\end{array}$ & Occupation & $\begin{array}{l}\text { Number } \\
\text { of } \\
\text { children }\end{array}$ & Age & Class & $\begin{array}{l}\text { School } \\
\text { type }\end{array}$ & $\begin{array}{l}\text { Working } \\
\text { Status of } \\
\text { spouse }\end{array}$ \\
\hline 1. & Nia & 36 & $\begin{array}{l}\text { Post- } \\
\text { graduation }\end{array}$ & Middle & Karnataka & Unemployed & Housewife & 1 & 7 & $2^{\text {nd }}$ & HFS & Employed \\
\hline 2. & Sana & 37 & $\mathrm{PhD}$ & Middle & $\begin{array}{l}\text { Uttar } \\
\text { Pradesh }\end{array}$ & Unemployed & Housewife & 2 & 2,8 & $2^{\text {nd }}$ & HFS & Employed \\
\hline 3. & Joya & 35 & $\mathrm{PhD}$ & Middle & Delhi & Employed & Teaching & 2 & $5.5,2$ & $1^{\text {st }}$ & HFS & Employed \\
\hline 4. & Priya & 37 & $\begin{array}{l}\text { Post- } \\
\text { graduation }\end{array}$ & Middle & Delhi & Employed & Teaching & 2 & 3,13 & $\mathrm{PP}, 7$ & HFS & Employed \\
\hline 5. & Rita & 30 & Primary & Lower & Delhi & Unemployed & Housewife & 2 & 7,9 & $2^{\text {nd }}, 4^{\text {th }}$ & LFS & Unemployed \\
\hline 6. & Soni & 35 & $\begin{array}{l}\text { Post- } \\
\text { graduation }\end{array}$ & Middle & Delhi & Employed & Administration & 2 & 3,13 & $\mathrm{PP}, 7$ & HFS & Employed \\
\hline
\end{tabular}

(HFS*: High fee school, LFS*: Low fee school, PP*: Pre-primary)

\section{Data Analytic Strategy}

The thematic analysis method was suitable to analyse the responses of this study as it "included questions about people's conceptualisations or ways of thinking about particular social phenomena" (Willig, 2013, p.183). It is a method of analysis that is used to understand and organise qualitative data. It has also been used to understand people's perception of other infectious diseases like AIDS and the Ebola virus (Joffe, 1999 and Joffe \& Haarhoff, 2002, cited in Willig, 2013, p.183). So, it was also well suited to explore women's experiences about child care during the COVID-19 pandemic. In its six-step process, researchers identify meaningful patterns and themes by consciously interpreting, discussing codes, and keeping the central research question in mind (Braun \& Clarke,2006; Clarke \& Braun, 2013; Willig, 2013). Therefore, we applied all six steps suggested by Virginia Braun and Victoria Clarke (2006, 2013). We transcribed recorded interviews and subsequently translated them into English. All researchers read each interview separately to understand women's experiences and backgrounds fully. Then initial codes were generated, reviewed, refined by mutual discussion. Afterwards, we generated broader themes and 
subthemes and found patterns in all themes. Over a series of online meetings, we reached a consensus about three generated themes with underlying sub-themes finally chosen to discuss the findings.

\section{Results and Discussion}

In this section, we present the themes identified by us and the discussion of the same, keeping in mind the objectives of this study.

\section{Multi-Layered Disruptions and Changes in Behaviour}

The COVID-19 crisis has caused multi-layered disruptions and behavioural changes in women's and children's lives. On the one hand, numerous challenges have popped up in front of all the parents, especially women, due to the closure of the early child care centres, work from home, loss of jobs, and online classes. On the other hand, mounting infection cases and deaths in India, the spread of misinformation, poor management in hospitals, scarcity of medical resources, slow vaccination process, and news of the third wave of infection where children may be more susceptible to an infection created chaos for everyone, particularly to the women having young children. Though challenges of women about childcare are argued in various researches (Del Boca, Oggero, Profeta, \& Rossi 2020; Guy \& Arthur, 2020; Weaver \& Swank 2021), there is a dearth of research highlighting the challenges of nuclear family women having young children and facing the pandemic. Based on exploring these women's experiences, the study result shows that both women and children were intolerably entrapped in COVID-19 induced labyrinths. The situation becomes more complicated in the Indian urban nuclear family context, where child care is a complete responsibility of mothers, paid or unpaid, and fathers are generally late entrants in early care (Das \& Zumbyte, 2017). The findings show that they have been facing manifold disruptions and changes in their behaviour. Under the theme, participants reported three types of significant disruptions: changed notion of home, exacerbation in responsibility, and unemployment, which further changed the behaviour of women and children in the play and social interaction domain. These are discussed below:

\section{Changed Notion of Home}

The COVID-19 pandemic has blurred boundaries of home, work, family life, and child care. Along with positive experiences, it has hard-pressed negative experiences. Chung, Seo, Forbes, and Birkett (2020) suggest that the working capacity of mothers who have children has dropped more than those without children. One reason for the decline in working capacity can lie in the changing concept of home due to the ongoing COVID-19 pandemic. Most women's responses show a similar pattern about the changed notion of home. In their views, due to lockdown and the threat of infection, a home has become a parallel site of office, school, and playground. In this case, they face problems ranging from the execution of multiple institutional activities at one place to the availability of limited space led to chaos, reduced discipline, and disruption of routine. They were having all activities like kitchen work, e-office of either one or both spouses, or having virtual classes of children simultaneously in the same location created hassle for the women.

As Priya, a teacher, having the responsibility of looking after two children and whose husband recently recovered from COVID -19, states,

"The classes of my children are conducted at the same time when I have to teach online."

The availability of limited physical space and electronic devices with internet connectivity is the major challenge.Sana, a 37-year-old, migrated from Delhi to Lucknow due to COVID, left her postdoc job due to the responsibility of taking care of two children without the support of her husband, who is on COVID testing duty, states:

\footnotetext{
"I wake up around five before the kids wake up because I have to make some arrangements, I have to clean home and sanitise groceries; I am afraid that kids may touch here and there, especially small ones. It is very tough for me to keep him away; they neither understand nor listen to my advice. So, I am very tired, very-very tired."
}

The majority of women show similar concerns about completing work within time in limited space, along with childcare and sanitisation of items purchased from the outside. Although home retained its safe 
status during the pandemic for everyone, the pandemic has created many challenges for women who live in nuclear families and have young children. The above narration reflects how the absence of a boundary between home, work, school, and playground escalated the tensions between work and family roles and added responsibilities of the woman. When everyone, including the pet animal of the family, shares the same room, office duty, domestic works, and the responsibility of young children intrude on each other, causing disruption (Olekalns \& Kennedy, 2020). It also clarifies that home is also changing its meaning to a considerable degree for women of nuclear families during the pandemic. The underlying properties of a home, as its size, structure, spaciousness, freedom, roles, responsibilities, silence and tranquillity, are responsible for making people comfortable during the pandemic (Yalçın \& Düzen, 2021), are missing in the lives of the participant women.

\section{Exacerbation in The Women's Responsibilities}

The COVID-19 pandemic has exacerbated many fault lines for women with young children. During the lockdown period of more than one year, from increased pressure of childcare to absence of domestic support to increased attention andmultitasks, all have created a distrusted lifestyle for women, further painting a poor childcare picture for children. Many research and recent reports (Chauhan, 2020; Guy \& Arthur, 2020) show that women usually share a load of childcare and domestic responsibilities. In India, societal norms of a good wife, mother, and motherhood exert pressure on women to keep their childcare responsibilities on the top. The women who cross these norms especially working mothers, are discriminated against and negatively evaluated for paying less attention to their offspring (Boudet, Petesch, \& Turk, 2013). Furthermore, the pandemic has thrust more childcare burden on women's shoulders and other responsibilities with unexpected changes. The pandemic's exceptional and high risky nature has created a situation where mothers feel depleted and lacking in their childcare engagement resources.

Nia, a 36-year-old, left her job due to the responsibility of a child, states:

"I think it was a great decision for me because, during this pandemic, you know my God! What Burden increased like anything."

Considering quitting the office job as a great decision shows her conformity to existing gender norms, where patriarchy favours men and limits women's chances of returning to the job sector. The use of the word "burden" just at the beginning of the interview shows how much she carries the weight of extended responsibility on her head. It can be inferred that the pandemic has aggravated social structural oppression. And in a very shrewd way, it brings back patriarchy, where household and care work are only assigned to women and kept in the downgraded category. All other participants also talked about their extended roles and responsibilities. Their narration shows how they have been trapped in a labyrinth of multiple responsibilities. The imposition of different roles at the same time caused their lives almost havoc.

Women show their depository of roles as becoming a mother, wife, domestic worker, carer, child's teacher, and employee. Having young children creates more challenges for women, as Sana shared how her two-year-old child starts rolling and moving up on the bed. Along with that, children of early childhood age are less attentive, create difficulty in following safety measures, naughty and annoying, and need more energy consumption on the part of women.

Work during the night has also emerged as a new pattern for some of these women. It explicitly reflects that there is hardly any distinction between personal and professional lives as both are limited to the household, which means women have to take up their professional commitments and domestic duties concomitantly. It can have an adverse impact on women's progress and wellbeing. Consequently, women have less time to invest effectively and strategize their career-related progress (Chauhan, 2020). Mainly, all women reported increased tiredness and sometimes inefficiency in tackling multiple tasks together, including childcare. Exacerbating responsibility for a long time may take a toll on women's health where chances of less focus on tasks haveincreased and engagement in multitasks also drain cognitive resources, and reduce the productivity of human beings (American Psychological Association, 2006).

\section{The State of Unemployment}


A UN (2020) report titled "Policy Brief: The Impact of COVID-19 on Women" suggests that women's lives can be affected differently and disproportionately on finances and productivity. It is crucial to admit that women have lagged in securing formal and high-paid jobs, receiving low wages, and having low social security even before the pandemic. But the COVID-19 pandemic risks rolling back the already achieved low progress of women in labour participation and constraining their presence due to lack of childcare support and increasing care demands at home. At the same time, women belonging from the middle and lower sections of society are more prone to bear the risk of reduced income, job loss, low self-safety, and increased and unpaid child care burden, which can negatively impact their overall well-being and also affect children's development.

The findings of the current study affirm the above statement. By reviewing the data, unemployment also has emerged as another significant issue in the interview. Three out of six respondents had to experience forced unemployment due to the full-time responsibility of childcare as childcare centres were closed during the pandemic. Women respondents are facing a different degree of impact due to their socioeconomic class position.

Sana, who belongs to the middle class, was working as a postdoctoral fellow, having the responsibility of two children aged two years and eight years shared her experience of leaving the job as:

\footnotetext{
"Little, very tough to explain because it is very hard. From the past 15 years I was working continuously without a break, and it is more of financial independence for me that I am working, getting a salary. After the pandemic, if the situation goes over and even after I want to go and look for a job, there is no job first. Second, I am from life sciences, so there are only COVID testing positions in the lab. That I cannot do it because of small kids."
}

It shows how women from nuclear families and having no childcare support are vulnerable to economic insecurity and experience loss of self-esteem. The adverse circumstances and tortured mental health of women can harm children's care and development too.

Rita, having two children and educated at the primary level, worked in a factory, was unable to go for the job due to lockdown, and her spouse also became unemployed due to similar reasons. She shared with the researcher,

"We are not able to go to duty, so we are even not getting the salary. Our room rent keeps on increasing as we are not in a position to pay it."

Her silence and murmuring in response to some questions during the interview indicated her hardship. Her condition reflects that she has less protection against dismissal from the job and doesn't have the benefit of paid leave due to her employment in an informal job sector (Rivera, Hsu, Esbry, \& Dugarova, 2020). The narration also reflects that living without a job is an odd experience for her. Moreover, the unemployment of both parents is putting a greater risk for their children's developmental and educational opportunities as survival has become a significant issue in this case. Emerging research, for example, Finnegan (2015), also indicates that mother and father's involuntary job loss could affect children's development, such as academic achievement and future aspiration. Simultaneously parents may be less supportive and engage in children's homework and school-related activities. Mari and Keizer (2021) and Hill, Morris, Castells, and Walker (2011) also argued a similar concern about the linkage between parents' job loss and child development. Results show that income loss of parents triggers depression, and it leads to negative maternal parenting, which resulted in problem behaviour in children and reduced verbal ability during the early childhood period. It shows how lower social class, less education, and job loss have created the most brutal punch on women and children and pushes their lives at risk.

\section{The Play During the Pandemic}

The COVID-19 situation has forcefully twisted the play behaviour of all young children. The United Nations Educational, Scientific, and Cultural Organisation (UNESCO,n.d.-a) report argues that play is a "powerful, scalable and effective" (p.1) way to maintain children's learning, health, and well-being during the COVID-19 pandemic. However, our study findings suggest that COVID-19 pandemic induced lockdown and fear of infection has served limited play opportunities, reduced physical activities, shrunk friends' circle, crafted less interaction, lack of learning, and low prosocial behaviour for children who fall 
in the early childhood stage and also denoted with the age of play.

This change has affected women and children differently, where on one side, women's multiple roles have become more complex and burdensome due to additional and unpaid labour (Cook, 2021) and the absence of children's lost play space and missing support of their playmates. On another side of this, the changed and complex notion of home, loss of finances, and other aggravating responsibilities during the pandemic are concurrently meditating with children's lives and affecting their play behaviour, social interaction, and development differently. For example, a participant, Soni faced too much difficulty managing children's play behaviour when her husband was hospitalised due to the coronavirus infection. Her experience of managing children's play behaviour becomes complex due to the intersection ofmultitasks, nuclear family type, and closure of early childhood centres.

Therefore, at the primary level, the challenge of channelizing children's energy in the absence of their teachers, friends, peer group, and play space while living in a nuclear family setting has been a significant issue for all mothers. About play behaviour in the pandemic, a participant, Sana, narrates about her child that:

"...sometimes he cries that mamma you don't allow me to play outside, but I tell him to maintain a physical distance.

I allow him when there is no kid outside. If there are kids, I always say to him, 'No'."

It reflects how the pandemic has made outdoor play space perilous for children, and playing without friends and just waving hands to each other has become a new normal during this challenging time. Even an uncertain pause is to continue going on indoor play activities with friends too. The analysis also suggests that the multi-story apartment's lives further reduce the children's chances of play in the absence of extra space, even those who have availability of roofs, their congested location and fear of coronavirus in the air has deprived them of free play opportunities.

Nia observes that children starved of the playground and stared at it while standing in their balconies and reports,

"We couldn't allow them, so that's why it's very frustrating. Twenty-four hours with the same routine, same room and all, so it is very boring for us as well as for them also."

It clearly shows children's inactivity and hopelessness, and their silence can be a worrying sign for their future. After the analysis, we can say that "pandemic play" has become more troublesome for all children, but children belonging to disadvantaged families face a significant threat as all the activities are operationalised under a single rented room.

In addition, younger children's play has taken a unique shape in the ongoing pandemic. Online gaming and digital mode of play have totally replaced friends and playgrounds now. The majority of participants reported how their children became more addicted to online games and videos. Moreover, the mobile phone has become a new toy for almost every child. The high indulgence in digital devices is creating health issues for children's majorly eyesight issues. One reason for increased involvement in online gaming is reportedly multitasking and the busy schedules of women.

This type of zero-free play zone or partial play, and total dependence on online play mode, can have a unique, harmful, and destructive impact on children's future lives. The ongoing pandemic situation can toll on children's physical health, social interaction, and various developments. Play with other children provides the opportunity to show off big feelings like anger and other emotions (Rushton, 2011,cited in UNESCO, n.d.-a). It helps in the development of language, learning of cooperation, and sharing (Piaget, 1999; Vygotsky, 1986), help in dealing with uncertainty, do coping with stress, learning of adult role and simultaneously also facilitates discoveries and problem even by searching some 'frivolous problems' (Chu \& Schulz, 2020, p.332). Bongiorno and Quinn's (2021) statement that "play is a part of a child's resilience toolkit" has been almost missing and leaking from the pipeline in the pandemic. Stuart Brown argued that the catastrophic impact of play deprivation during the early years is linked to less flexibility in thoughts, poor anger management, and fragility in interpersonal relationships (Brown, 2014, cited in Hanscom, 2021).

\section{The Social Interaction During the Pandemic}


Children are also missing other kinds of social interaction during the pandemic with play deprivation, especially with nature and their close surroundings labelled as the "Meso system" in Urie Bronfenbrenner's ecological system theory. It is an established fact that peer talk, sibling talk, doing things together, going outside, observing their surroundings, and learning the symbolic language all play an essential role in meaning-making among children. The meaning-making process needs an active engagement on the part of children to transform their knowledge with the help of language. Through this process, they understand the social reality. Social interaction with others is also helpful to build social and communication competence. In social interaction and play, children resist, negotiate, and achieve a state of inclusion in the peer group.

However, the current COVID-19 pandemic has forcefully put a pause on all these types of social interaction among children, especially among younger ones. The study results show that children are experiencing unique effects of lack of social interaction in the pandemic, responsible for producing some novel social behaviour in themselves. We interviewed about children's social interaction, and participants explained the high level of decline in this domain. Almost all interviewed women mentioned a drastic change in children's social interaction during the pandemic. The findings of this study suggest that pandemic-induced social changes experienced by children are loss of their soft and friendly nature, deteriorating social skills, including no routine, poor discipline, and lacking basic etiquettes.

The lack of social interaction may generate an unusual type of social development. A participant, Sana, discussed how her two-year-old child confronted touching and showed disgust in meeting someone. She added,

"If someone is smiling, so he is very strange, why is he smiling at me? He doesn't give a smile back. He gives a weird expression because he has not seen this. He has grown up in the pandemic."

It shows the social deprivation effect on a child's behaviour where the child has been showing irritability due to human contact. It also shows that being isolated, lonely with less interaction may have a different prospect for children. Toran, Sak, Xu, Şahin-Sak and Yu (2021) also affirm our study's findings, where researchers revealed how Turkish and Chinese parents noticed children's changed behavioural characteristics during the quarantine process. The compromised caregiving environment, cold attitude of parents, low warmth, less and unsupportive interaction may aggravate adversity for some children who may show low verbal ability and affect their socio-emotional well-being (Odgers \& Jaffee, 2013).

The findings of our study show that women face multiple types of adversities that, in turn, may affect the children in the form of less support and disrupted caring and may also create an environment of low social interaction. Consequently, less support and women's overall well-being may significantly influence overall childcare patterns and children's social interaction.

It can be inferred from the above discussion that social interaction, which is part of a child's immediate neighbourhood and the child's school, has been plucked from their lives due to the pandemic. Consequently, children are not only missing classes or school but are also missing uncomplicated everyday interactions like walking to class together, eating lunch together, playing, learning and creating together. The long-term closure of educational institutions in India has put children into inexorable circumstances, leading them into unusual experiences beyond normal. As a result, they experience stress, anxiety and seized freedom.

\section{Remote Learning: An Emerging Concern}

Coronavirus pandemic has also wreaked havoc and brought education to a halt by school closures and brought new normal learning for the students, particularly remote learning. This type of learning is globally promoted and presented as an alternative to face-to-face classroom learning. Although there were specific online learning platforms available before the pandemic in India like Byjus, Meritnation, Vedantu, and more, they were optional and not forced. However, now forcibly, whether desirable or not, every child must go through remote learning to study. This no-choice approach of changing homes to classrooms in a 
hurry presents mammoth challenges for parents and children, both human and technical. UNESCO(n.d.b) also highlighted the adverse consequences of school closure.

Women with children from the early childhood stage have to face the brunt of this pandemic more. The women have to go through various challenges of remote learning as the Covid-19 pandemic has made digital technologies the only lifeline for education. However, the pandemic has not come with a hierarchical approach in spreading the infection to the privileged and non-privileged, but remote learning accompanying those socio-economic differences and thus shone a stark spotlight on the educational disparity (Gross, 2020). The pandemic induced sharp and sudden alteration in learning mode presented various concerns for everyone. Like various scholars have also insisted that online learning is not a good exposure for young children, limiting the socio-emotional readiness of children for school (Edwards, Skouteris, Rutherford, \& Cutter-Mackenzie, 2012). The parents are not happy with this type of learning due to several subjective reasons. Researchers also explained that young children have a short attention span, thus unable to engage them in online learning (Dong, Cao, \& Li, 2020). Most participants complained about the non-engagement of the children, talked about their inactiveness, and spoke about the "zero discipline" during these online classes. According to Nia,

"...remote learning was totally a 'Flop Show'with my son as he didn't want to sit in one place. In the beginning, we had to struggle a lot, I had to sit with him, it was really horrible".

The findings of our study confirm the above narration that most of the mothers have to sit with their children during the online classes as sometimes they are unable to understand, face difficulty noting down homework for each day, and need help in submission. Owing to the nuclear nature of the family and the existence of skewed gender norms in society that a child's education and care is a woman's responsibility, the situation becomes more typical.

The present research reports that remote learning is loosening parents' purse strings as they have to purchase an extra phone or device for online classes. Hence, the families who cannot buy an extra phone have to make their children attend classes from their phone only, so if they have to go outside, they have to wait for their work. They also have to arrange $\mathrm{Wi}-\mathrm{Fi}$, a webcam, and other necessary resources for taking the classes. Almost every school is giving now online classes on "Zoom," "Google Meet," and "Microsoft Teams" except some low fee schools providing study material for online classes through "Youtube" links and messages on "Whatsapp".

So, one can imagine the quality of education of those low fee schools that are teaching by just sending messages and study material on Whatsapp. The child is just copying the material from it and not understanding anything, nor the illiterate parents can make them understand. Thus, it is proving more typical for low SES children whose parents are uneducated, on the verge of losing their job, and have fewer learning opportunities beyond school.

In addition, prolonged screen time also has been putting a high level of strain on young ones' eyes. Emerging research also notes that the effect on children's eye vision is the most prominent one during this time (Dong et al., 2020). Another study also identified that three to six-year-old children stayed for a long time with mobile phones and electronic screens during the COVID-19 (Toran et al., 2021). Almost all the participants showed their serious concerns regarding their child's eyes due to these online classes. According to Priya,

"...first my son started to get water in his eyes and had to put on specs and then my daughter who just took admission in the preschool started to get problems in her eyes."

So, it is clear that one has to study at the cost of eye strain, face headaches, blurred vision, and adjust to the condition of dry eyes (Peterson \& Salem, 2021). The study's findings show that the online learning device is drowning the throat by the pandemic, and getting universal acceptance has also created more psycho-physical disturbances among children.

United Nations Children's Emergency Fund ([UNICEF], 2020a) report has pointed out the harmful content available on the internet, leaving the child vulnerable and tortured. Some interviewed women tried 
to overcome this problem by replacing the mobile with desktop and smart TV. The reason was to give a big screen instead of a small one and check whether the child is taking the classes or opening something else. Like Soni states:

"...now, due to smart TV, I can watch what the child has opened, as sometimes the child used to open something that is not good for their mind."

On the one hand, it shows that women have to be highly vigilant about the harmful content on the internet and the risks of unrestricted digital use to sail in this new reality. The proliferation of internet access and mobile technology is also stressing to implement the UNICEF (2020b), "Guidelines for Industry on Child Online Protection" which offers protection of child rights from sexually abusive material, create an age-appropriate and safer online environment, to educate children, parents, and teachers about the safe and responsible use of ICT. The other side also exposes the need for secure and appropriate age kids' content on digital media platforms in this pandemic time that can join the people instead of shutting them out (Hasinger-Das, Brennan, Dore, Golinkoff, \& Hirsh-Tasek, 2020). As for many women and children, it also becomes a source of engagement with their friend circles. In the long run, this type of learning will also be a challenge for low SES children as it increases the probability of pushing out more than the retention of them. It can result in much more disruptions that exacerbate the already present gap in our education system.

\section{Mental Health and Well-Being of Women and Children}

\section{Mental Health and Well-Being of Women}

The mental health and well-being of women and children have received the worst hit during the COVID-19 pandemic. All the above-discussed themes have been filled with an abundance of disruptions, typicalities, hassles, insecurities, and inefficiency in strategising on the part of women. Consequently, it may paint a poor picture of women's mental health and well-being. The causal relationship of the mentioned challenges is grounded in our society's social structure, which compels only women to bear the burden of caring responsibilities. The study's findings revolve around three central lived realities of women belonging to nuclear families. These are heightened psycho-socio-economic anxieties, compressed existing support systems, and fragile coping strategies.

For each woman we have interviewed, fear of infection, work-home balance, extended child care, education, and reduced income have taken a toll on their mental health and well-being. As Sana, unemployed during the pandemic, having two children, states,

"...for the first time in my life, I have to depend on anxiety tablets, even during the hardest times I have tackled it all the way, but never -ever I have seen such time, but this time I break down."

Her weepy voice during the interview shows tremendous pressure on her mind due to unexpected added responsibilities and the risky job of her spouse, which she metaphorically related to the feeling of "constant sitting on the dynamite".

The pandemic-induced lockdown forced all the family members to stay together 24 hours; this situation presented a panorama of challenges, especially for women. Consequently, many respondents elucidated significant changes in their mental health in the form of frustration, tiredness, disappointments, extended fear, anxieties, and aggravated conflicts with their spouses. The fear of deterioration in participants' age and unsuccessful attempts to get a job in the pandemic also exacerbates the tension level of some participants. Simultaneously, the pandemic provoked a monotonous routine, and restriction on movements also has a toll on women's psychological well-being. Most of them reported a general feeling of boredom. It shows how due to deprived social interaction and engagement, women have been facing solitude. Campbell (2020) also mentions that fear of infection, social isolation, inadequate health, less communications, and the loss of jobs or income are responsible for generating negative emotions in human beings.

Support system contributes to the psychological wellbeing of individuals (Reblin \& Uchino,2008). Getting support in the time of stress can have a boosting impact on the overall wellbeing of a person. There 
are various support systems that a woman having children is looking up to, like schools, day-care centres, domestic help, or help from the spouse in household chores and childcare responsibilities. However, where on the one side COVID-19 pandemic has extended the anxiety level of women, on the other side, it has restrained all the possibility of getting support.

The findings of our study reflect the grim side of support of women during the pandemic. Due to the gendered nature of housekeeping work, women are compelled to bear this burden alone. The analysis of lived experiences of nuclear family's women explicitly shows that they are not getting any institutional, family, financial, and market-based support during the pandemic.

Nia expresses the pandemic phenomena as a "horrible experience" just at the beginning of the interview. She states:

"Pandemic obviously is not good, it is horrible, but we can say that all the work pressure is there on my shoulder whether it is the education of my son and the domestic work... all totally on me. I have to do it. I have to finish all the work early then only the other work starts on time."

It shows the bleak picture of women juggling many family responsibilities, and with no constant support from any source, their well-being is in danger. However, it is also an emerging fact that humans thrive for survival in any conflict setting and prolonged deprivation of support. The Neuro P5, power, pleasure, profit, pride, and permanency that drive the nature of a person induced a desire for human survival and extending life. These drives also make people feel good (Al-Rodhan,2019).

Given the above fact, Lazarus and Folkman's (1984) theory also emphasised how individuals constantly change their cognitive and behavioural efforts to manage inner and outer threats and warnings. The analysis of women's narration also gives a clear picture of their thriving and surviving through the use of fragile coping strategies.

During the ongoing COVID-19 pandemic, all women were learning to use approach-avoidance in frightening situations, taking breaks from watching news stories, gradually accepting and adjusting with lockdown-induced uncertainties, connecting with close ones using digital technology, and adapting meditation practices.

Joya's expression gives the impression of her coping strategy to mitigate negative experiences and stress. She listens to music, talks to friends over the phone, gives "me-time" to practice self-care to maintain her fluctuating mood. Another participant, a teacher, used her acquired academic skills like role-playing with her children to minimise boredom during the pandemic. However, it is essential to admit that all listed coping strategies are only in their hit and trial phase, subjective and contextual. One of the participants, Sana, mentions,

"I will say I don't cope with it; I am still struggling."

Her state shows how coping in the pandemic is fragile in nature, where a person is still wrestling to find a state of contentment and well-being.

\section{Mental Health and Well-Being of Children}

Not only women have faced multiple stressors which adversely affected their mental health and well-being in COVID outbreak, but also children can face more adverse effects even in the coming years of their life (Singh et al.,2020). It is a comprehensive fact that early experiences contours the blueprints of the developing brain; they also prepare the way of sound mental health (Chen, 2016). Therefore, any disruptions to this developmental process can impair a child's capacities for learning and relate to others which have lifelong implications. The National Institute of Mental Health and Neuro Sciences (n.d.) (which run under the aegis of the Government of India) came up with an essential document for children's mental health; likewise, the CHILDLINE India foundation and UNICEF collaborative efforts for the production of essential children's mental health resource toolkit, signify the inevitability of crisis in some sense. Despite such interventions, various researches show the harsh truth of children's mental health and well-being. For example, a 50 percent spike has been seen since lockdown to avail pandemic-related information on the 
CHILDLINE, a child service helpline of the Ministry of Women and Child Development, India (CHILDLINE \& UNICEF India, 2020).

On these notes, our study findings also show various kinds of mental health-related challenges among the children. There is a noticeable change in the behaviour of children. Interviewed women inform a diverse range of psychological discomforts of their children, such as boredom, heightened anguish behaviour, increased clinging, increased disobedience, becoming much stubborn, and showing tempertantrum. Lee (2020), Liu, Bao, Huang, Shi and Lu (2020), and Zhai and Du's (2020) study results also confirm our findings. Having two children aged 2 and 5 years old, Joya briefs how it has become too difficult for her to manage her child's crying behaviour, who every time insists on going outside. It creates more typicalities in front of the mother as the child's young age comes ahead as a barrier to understand the importance of safety measures during the lockdown. The analysis also suggests that the child's young age also creates communication barriers, making it difficult for mothers to engage in playful activities with them, leading to loss of interest and unwillingness in children, resulting in reduced interaction and indulgence with adults. The impoverished parent-child interaction may profoundly impact children's development (Odgers \& Jaffe, 2013). Women also reported that children have an enhanced inactive and silent state during the pandemic that is covertly disturbing children's mental health, which is generally unrecognised and ignored by the parents due to their limited knowledge in child development.

However, it is essential to mention that even confronting such multi-layered responsibilities with tensed mental resources, women have been taking various forms of initiatives to engage their young children. Examples of such activities are reading books, gardening, cooking, baking, role-playing, yoga, meditation, and more. The online mode of learning has also emerged as an essential engagement strategy. For example, a participant's son uses email and Hangout to chat with his friends. It reflects that some children whose mothers have sound knowledge about using electronic communication quickly learn these skills and adapt to the changing environment. Nevertheless, women are not entirely successful in utilizing their greater energy levels due to their time-bound work, unconfident children engagement plan of action, and extended responsibilities.

\section{Conclusion}

The purpose of the present study was to achieve a better understanding of nuclear family women's childcare experience in the face of the COVID-19 pandemic. Usually, in no part of the world parents had raised their children in secluded nuclear compartments as they are compelled to do now. Due to the outbreak of this pandemic, women from a nuclear family got a barrage of responsibilities, causing confusion and feeling of helplessness in them. Undoubtedly, the pandemic weighs heavily for all of us, but it has revealed how shaky our nuclear family foundation is. This study provides an opportunity to comprehend the lived reality and significant perspective of women and is able to gauge how the pandemic situation has changed the notion of home for women and children both in different ways.

On the one hand, living continuously at home has presented different struggles for women, especially in nuclear families, where under one roof with young age children, increased diverse roles and responsibilities, heightened helplessness and vulnerability, readjustment with job loss, with less support system and spoiled mental health they are living almost a miserable life. Consequently, women's childcare trajectories are becoming gruelling and further limiting the chances of optimum development. On the other hand, children's lives also come under a tattered umbrella with the imposed COVID restrictions and the changing ecology of home and mother. Zero-free play zone reduced social interaction, forceful remote learning, vulnerable mental health, almost caged childhood, and much more disruptive behaviours are the prominent endowments of the COVID-19 to children in the early childhood stage. All these adversities are spreading their wings silently, putting little ones into caged childhood and leaving them with burdensome childcare experiences.

Our study results are meaningful in such a way that it not only understands the interconnecting and reciprocal nature of pain and gain of women of nuclear families but also maps explicitly the impact of 
changing nature and nurture on developmental opportunities for early childhood during the pandemic. The outbreak realises that the demand for a stable support system for childcare is not a luxury on the women's side. However, it is essential to achieve and maintain gender equality while simultaneously providing holistic developmental opportunities to children. In this connection, remote learning has also become a new normal as it has added a new dimension in early childhood education. A complete makeover is experienced in children's play behaviour where the phone has closer proximity in children's minds. It can be inferred that the digitalised world has become more knowledgeable for children than parents. Results also show that the pandemic affects individuals differently based on their underlying social context and social class positions. Comparatively, low socio-economic security and less education have a more drastic effect on the overall well-being of women and children, reflecting the urgent need for meaningful interventions to provide sustainable support to them.

Contributing to the original knowledge, research shows that women and children are becoming more resilient even with the gruesome reality of the pandemic. They are adapting differently to the changing environment, and somewhere their capacities have also increased to handle such shocks in the future. This crucial time also provides some new choices to rethink parents, teachers, and policymakers about how early childhood education and development can be saved from the flood of digitalisation and marketisation. We suggest that there is a need to find out contextual measures to develop children's competence. Moreover, children and women's mental health and well-being emerged as an important area to be taken care of seriously, individually and collectively, by all stakeholders.

It is vital to admit that this study is not without limitations. We think three main initiatives could provide a more nuanced picture of women's and children's overall well-being. This strategy will include the need for closer observation of children's overall behaviour, direct visits to the research fields, and listen to men's perspectives.

In the end, we will say that women's lived experiences about child care provide us with a critical lens to understand the struggles of their real social world. They are also crucial for setting the foundation of a progressive society. But the big question remains: how will we really change this scenario in the coming future? One hopes that at present, lies in collective efforts and togetherness.

\section{Declarations}

Acknowledgements: Thanks are due to our respondents who have given their valuable time to the study. The authors also would like to express deep gratitude to their mentor, Dr. Arvind Kumar Mishra, for reviewing and editing the paper. However, the authors are solely accountable for any lapse.

Authors' contributions: All authors have contributed equally to this paper.

Competing interests: The authors declare that they have no competing interests in this paper.

Funding: This research was not supported by any funding.

\section{References}

Al-Rodhan, N. (2019, April 4). A neuro-philosophy of human nature: Emotional amoral egois and the five motivators of humankind. [Blog Post]. Retrieved from https://blog.apaonline.org/2019/04/04/a-neuro-philosophy-of-human-nature-emotional-amoralegoism-and-the-five-motivators-of humankind/?amp\#referrer=https $\% 3 \mathrm{~A} \% 2 \mathrm{~F} \% 2 \mathrm{Fwww}$.google.com\&amp tf=From $\% 20 \% 251 \% 24 \mathrm{~s}$

Allendorf, K. (2013). Going nuclear? Family structure and young women's health in India, 1992-2006. Demography, 50(3), 853-880. https://doi.org/10.1007/s13524-012-0173-1 American Psychological Association. (2006). Multitasking:
https://www.apa.org/research/action/multitask

Anderson, C., Kraus, M., Galinsky, A., \& Keltner, D. (2012). The local-ladder effect: Social status and subjective well-being. Psychological Science, 23(7), 764-771. https://doi.org/10.1177/0956797611434537

Bongiorno, L., \& Quinn, K. (2021). The impact of play deprivation. Retrieved from https://www.psychologytoday.com/us/blog/optimized/202104/the-impact-play-deprivation 
Boudet, A. M. M., Petesch, P., \& Turk, C. (2013). On norms and agency: Conversations about gender equality with women and men in 20 countries. Washington DC: World Bank Publications.

Braun, V., \& Clarke, V. (2006). Using thematic analysis in psychology. Qualitative Research in Psychology, 3(2), 77-101. https://doi.org/10.1191/1478088706qp063oa

Campbell, A. M. (2020). An increasing risk of family violence during the Covid-19 pandemic: Strengthening community collaborations to save lives. Forensic Science International: Reports, 2, 100089. https://doi.org/10.1016/j.fsir.2020.100089

Chakravorty, S., Goli, S., \& James, K. S. (2021). Family demography in India: Emerging patterns and its challenges. Sage Open, 11(2), 1-18. https://doi.org/10.1177/21582440211008178

Chauhan, P. (2020). Gendering COVID-19: Impact of the pandemic on women's burden of unpaid work in India. Gender Issues. https://doi.org/10.1007/s12147-020-09269-w

Chen, S. (2016, February 5). The significance of mental health in early childhood. [Blog post]. Retrieved from https://novakdjokovicfoundation.org/the-significance-of-mental-health-in-early-childhood/

CHILDLINE and UNICEF India. (2020). Psychosocial support for children during COVID-19 a manual for parents and caregivers. Retrieved from https://www.unicef.org/india/reports/psychosocial-support-children-during-covid-19

Chu, J. \& Schulz, L.E. (2020). Play, curiosity and cognition. Annual Review of Developmental Psychology, 2(1), 317-343. https://doi.org/10.1146/annurev-devpsych-070120-014806

Chung, H., Seo, H., Forbes, S., \& Birkett, H. (2020). Working from home during the COVID-19 lockdown: Changing preferences and the future of work. Retrieved from https://www.birmingham.ac.uk/Documents/college-social-sciences/business/research/wirc/eppworking-from-home-COVID-19-lockdown.pdf

Clarke V., \& Braun, V. (2013). Methods: Teaching thematic analysis. The Psychologist, 26(2), 120-123.

Cook, R. (2021). Covid-19 has been a crisis for women - but some governments have recognised this better than others. Retrieved from https://www.kcl.ac.uk/news/covid-19-crisis-for-women-government

Das, M. B., \& Zumbyte, I. (2017). The motherhood penalty and female employment in urban India. Policy Research Working Paper, No. 8004. Washington, DC: World Bank Group. https://doi.org/10.1596/1813-9450-8004

Del Boca, D., Oggero, N., Profeta, P., \& Rossi, M. (2020). Women's and men's work, housework and childcare, before and during COVID-19. Review of Economics of the Household, 18(4), 1001-1017. https://doi.org/10.1007/s11150-020-09502-1

Dong, C., Cao, S., \& Li, H. (2020). Young children's online learning during COVID-19 pandemic: Chinese parents' beliefs and attitudes. Children and Youth Services Review, 118, 105440. https://doi.org/10.1016/j.childyouth.2020.105440

Edwards S., Skouteris H., Rutherford, L., \& Cutter-Mackenzie A. (2012). 'It's all about Ben10 ${ }^{\mathrm{TM}}$ : Children's play, health and sustainability decisions in the early years. Early Child Development and Care, 183(2), $280-293$. https://doi.org/10.1080/03004430.2012.671816

Finnegan, A. (2015). Unemployment: How it effects family behavioral health amy finnegan, center for child and family policy. Retrieved from https://www.purdue.edu/hhs/hdfs/fii/wp-content/uploads/2015/07/s ncfis08c03.pdf

Gromada, A., Richardson, D., \& Rees, G. (2020). Childcare in a global crisis: The impact of COVID-19 on work and family life. Retrieved from https://www.unicef-irc.org/publications/pdf/IRB-2020-18-childcare-in-a-global-crisis-the-impact-of-covid-19-on-workand-family-life.pdf

Gross, H. (2020, April). Perspective during Covid-19, teachers can support students using Maslow's hierarchy of needs. Retrieved from https://www.ednc.org/perspective-during-covid-19-teachers-can-support-students-using-maslows-hierarchy-of-needs/

Guy, B., \& Arthur, B. (2020). Academic motherhood during COVID-19: Navigating our dual roles as educators and mothers. Gender, Work \& Organization, 27(5), 887-899. https://doi.org/10.1111/gwao.12493

Hanscom, A. (2021). Why play deprivation is serious problem. Retrieved from https://www.communityplaythings.com/resources/articles/2021/Play-Deprivation-is-a-Serious-Problem

Hassinger-Das, B., Brennan, S., Dore, R. A., Golinkoff, R. M., \& Hirsh-Pasek, K. (2020). Children and screens. Annual Review of Developmental Psychology, 2(1), 69-92. https://doi.org/10.1146/annurev-devpsych-060320-095612

Hill, D.H., Morris, A.P., Castells, P., \& Walker, T. J. (2011). Getting a job is only half the battle: Maternal job loss and child classroom behavior in low-income families. Journal of Policy Analysis and Management, 30(2), 310-333. https://doi.org/10.1002/pam.20565

International Labour Organization. (2020). As jobs crisis deepens, ILO warns of uncertain and incomplete labour market recovery. Retrieved from https://www.ilo.org/global/about-the-ilo/newsroom/news/WCMS_749398/lang--en/index.htm

Lazarus, R. S., \& Folkman, S. (1984). Stress, appraisal, and coping. New York: Springer publishing company.

Lee, J. (2020). Mental health effects of school closures during COVID-19. The Lancet Child \& Adolescent Health, 4(6)421.https://doi.org/10.1016/S2352-4642(20)30109-7 
Women and children's well-being in Indian nuclear families...

Liu J. J., Bao Y., Huang X., Shi, J., \& Lu, L. (2020). Mental health considerations for children quarantined because of COVID-19. The Lancet Child \& Adolescent Health, 4(5), 347-349. https://doi.org/10.1016/S2352-4642(20)30096-1

Mari, G., \& Keizer, R. (2021). Parental job loss and early child development in the Great Recession. Child Development, 0(0), 1-19. https://doi.org/10.1111/cdev.13517

Narayan, A., \& Bhardwaj, G. (2005). Dual career nuclear families in India: Attitudes and social support. Indian Journal of Industrial Relations, 41(1), 79-93. http://www.jstor.org/stable/27767995

National Institute of Mental Health and Neuro Sciences. (n.d.). Taking care of mental health of child during covid-19. Retrieved from: https://www.mohfw.gov.in/pdf/mentalhealthchildrean.pdf

Odgers, C. L., \& Jaffee, S. R. (2013). Routine versus catastrophic influences on the developing child. Annual Review of Public Health, 34(1), 29-48. https://doi.org/10.1146/annurev-publhealth-031912-114447

Olekalns, M., \& Kennedy, A. J. (2020). How couples can find balance while working from home. Retrieved from https://hbr.org/2020/12/howcouples-can-find-balance-while-working-from-home

Peterson, C., \& Salem, W. (2021, January). Remote learning impacting children's eyeside. Spectrum News 1. Retrieved from https://spectrumlocalnews.com/nc/triad/news/2020/12/31/remote-learning-impacting-children-s-eyesight-

Piaget, J. (1999). Play, dreams and imitation in childhood. London: Routledge.

Reblin, M., \& Uchino, B. N. (2008). Social and emotional support and its implication for health, Current Opinion in Psychiatry, 21(2), 201-205. https://doi.org/10.1097/YCO.0b013e3282f3ad89

Rivera, C., Hsu, Y. C., Esbry, F. P., \& Dugarova, E. (2020). Gender inequality and the COVID-19 crisis: A human development perspective. Retrieved from http://hdr.undp.org/sites/default/files/covid-19 and human development - gender dashboards final.pdf

Scharff, C. (2015). The psychic life of neoliberalism: Mapping the contours of entrepreneurial subjectivity. Theory, Culture \& Society, 33(6), 107-122. https://doi.org/10.1177/0263276415590164

Singh, J. P. (2003). Nuclearisation of household and family in urban India. Sociological Bulletin, 52(1), 53-72. https://doi.org/10.1177/0038022920030103

Singh, S., Roy, D., Sinha, K., Parveen, S., Sharma, G., \& Joshi, G. (2020). Impact of COVID-19 and lockdown on mental health of children and adolescents: A narrative review with recommendations. Psychiatry Research, 293, 113429. https://doi.org/10.1016/j.psychres.2020.113429

Suppal, P., \& Roopnarine, J. L. (1999). Paternal involvement in child care as a function of maternal employment in nuclear and extended families in India. Sex Roles, 40(9), 731-744. https://doi.org/10.1023/A:1018808718351

The Lancet (2021). India's COVID-19 emergency. 397(10286), 1683. https://doi.org/10.1016/S0140-6736(21)01052-7

Tiwari, G. K., Tiwari, R. P., Pandey, R., Ray, B., Dwivedi, A., Sharma, D. N., ... Tiwari, A. K. (2020). The life outcomes of children during COVID-19: Exploring the protective roles of the joint and nuclear families in India. [PrePrint]. https://doi.org/10.22541/au.159769493.33057412

Toran, M., Sak, R., Xu, Y., Şahin-Sak, İ. T., \& Yu, Y. (2021). Parents and children during the COVID-19 quarantine process: Experiences from Turkey and China. Journal of Early Childhood Research, 19(1), 21-39. https://doi.org/10.1177/1476718X20977583

Tuli, M., \& N. Chaudhary. (2010). Elective interdependence: Understanding individual agency and interpersonal relationships in Indian families.Culture and Psychology, 16(4), 477-496. https://doi.org/10.1177/1354067X10380157

UN (2020). Policy brief: The impact of COVID-19 on women. Retrieved from https://www.un.org/sites/un2.un.org/files/policy_brief_on_covid_impact_on_women_9_april_2020.pdf

UNESCO (n.d.-a). Play and early learning during COVID-19. Retrieved from https://en.unesco.org/sites/default/files/unesco-covid19_ed-webinar-14-right_to_play.pdf

$\begin{array}{llllll}\text { UNESCO (n.d.-b). Adverse consequences } & \text { of } & \text { school } & \text { closure. }\end{array}$ from https://en.unesco.org/covid19/educationresponse/consequences

UNICEF (2020a). Children at increased risk of harm online during global COVID-19 pandemic. Retrieved from https://www.unicef.org/documents/covid-19-and-implications-protecting-childrenonline?utm_campaign=coronavirus\&utm_source=referral\&utm_medium=media-

UNICEF (2020b). Guidelines for industry on child online protection. Retrieved from https://www.unicef.org/documents/guidelinesindustry-online-child-protection

United Nation Development Programme. (2020). UNDP and UN women launch COVID-19 global gender response tracker. Retrieved from https://www.undp.org/press-releases/undp-and-un-women-launch-covid-19-global-gender-response-tracker

Vygotsky, L.S. (1986). Thought and language. Cambridge, MA: MIT Press. 
Richa RANA, Ridhi SOOD \& Sonali BHARDWAJ

Weaver, J. L., \& Swank, J. M. (2021). Parents' lived experiences with the COVID-19 pandemic. The Family Journal, 29(2), 136-142. https://doi.org/10.1177/1066480720969194

Willig, C. (2013). Introducing qualitative research in psychology (3rd ed.). England: Open University Press.

Yalçın, M. G., \& Düzen, N. E. (2021). Altered meanings of home before and during COVID-19 pandemic. Human Arenas, 1-13. https://doi.org/10.1007/s42087-021-00185-3

Zhai, Y., \& Du, X. (2020). Mental health care for international Chinese students affected by the COVID-19 outbreak. Lancet Psychiatry, 7(4), e22. https://doi.org/10.1016/S2215-0366(20)30089-4 